\title{
DIE OORLEWING VAN DIE KLASSIEKE LETTERKUNDE
}

\section{GEDURENDE DIE MIDDELEEUE}

\section{DEEL 2 : DIE GRIEKSE OOSTE}

\section{W.J. Henderson, Randse Afrikaanse Universiteit}

Historici dateer die aanvang en fases van die Bisantynse periode verskillend. Sandys (1921:387) onderskei 'n vroee fase vanaf die stigting van Konstantinopel in 330 tot die dood van Heraklios in 641, 'n oorgangsfase van verval vanaf 641 tot 850 , en 'n laat-Bisantynse fase van opbloei van 850 tot die val van Konstantinopel in 1453. Harvey (1984:83) dateer die Bisantynse periode vanaf die sluiting van die Atheense skole deur Justinianus in 529. Hussey (1970:11), wat ook die stigting van Konstantinopel as die beginpunt neem, verklaar: "The very foundation of an eastern capital, the seat of the senior Emperor, pointed the way to the middle ages when it was the eastern half of the Roman Empire which survived without any break in its history. It is immaterial whether it is called early Byzantine or late Roman during this formative period inaugurated by Constantine the Great. It was essentially the Roman Empire and as such its culture was predominantly Greek, though with strong oriental influences" (vgl. ook 1970:12-13; Kazhdan \& Wharton Epstein 1985:1-2). Moss \& Diehl (1961:1-33) verdeel hulle oorsig in die periodes vanaf 330 tot die Vierde Kruistog in 1204, en dan weer tot 1453, terwyl Baynes in die inleiding (xv) die volgende waarskuwing van R.G. Collingwood aanhaal: "There are in history no beginnings and no endings. History books begin and end, but the events they describe do not".

Vir die geskiedenis van die oorlewing van Griekse tekste in die Ooste is daar drie kerngebeure wat deurslaggewend was: die Griekse "renaissance" van die 9de eeu, die eerste aanval op Konstantinopel deur die Frankiese kruisvaders (1204), en die inname van Konstantinopel deur die Turke (1453).

Vir ongeveer vier eeue na die stigting van Konstantinopel was daar in die Griekssprekende wêreld 'n geleidelike politieke, kulturele en ekonomiese agteruitgang. Daar was wel nie die invalle van Germaanse stamme op 'n skaal soos in die Westerse Romeinse Ryk nie, maar die konstante eksterne bedreiging van die Perse en noordelike stamme, en vanaf die middel van die 7de eeu die opkomende Islam het die militêre mag telkens getoets. Daarby was daar gedurig die interne twiste oor Christen-dogma en spanning tussen Staat en Kerk, en tussen Weste en Ooste wat hulle tol geëis het (Hussey 1970:14-31; Kazhdan \& Wharton Epstein 1985:2-10).

Keiser Julianus die Afvallige (361-363) het 'n biblioteek in Konstantinopel gestig wat egter in 491 afgebrand het. Daar was 'n ander biblioteek van kerkliteratuur in die paleis (Sandys 1921:381-382). Gedurende die bewind van Theodosius II (408-450) word die intellektuele lewe gestimuleer (Sandys 1921:363-381). In hierdie fase was die onderwys, staatsargiewe, private en openbare biblioteke, en, in 'n steeds toenemende mate, die Kerk verantwoordelik vir die oorlewing van die ou tekste, heidens en Christelik. Daar is egter 'n vernouing van die spektrum van antieke boeke wat nou nog gelees word: die fokus van die Kerk en onderwys het hier ' $\mathrm{n}$ beslissende rol gespeel.

Weinig manuskripte dateer uit hierdie periode, wat eintlik meer op kompilasiewerk gekonsentreer het (Reynolds-Wilson 1968:44-47). Tot die 5de eeu behoort Hesuchios wie se sitate uit Griekse skrywers in sy Lexikon dikwels tot die verbetering van die oorgelewerde tekste gelei het (Sandys 1921:378). Stephanos van Bisantium en Stobaeus, in die volgende eeu, versamel in hulle Lexika uittreksels uit talle skrywers. Laasgenoemde haal ongeveer 500 sulke 
skrywers aan (Sandys 1921:379, 380). Hierdie leksikograwe is dikwels ons enigste bron van bv. liriese tekste.

Teen die 6de eeu het egter net Konstantinopel en Alexandrië as kulturele en intellektuele sentra oorgebly (Sandys 1921:381-383; Reynolds-Wilson 1968:44). Die stryd rondom die ikoonaanbidding wat tot 843 gewoed het, het nie juis die belangstelling in Klassieke tekste gestimuleer nie. Leo III, keiser in Konstantinopel (717-741), inisieer die ikonoklastiese beweging (Sandys 1921:391; Moss \& Diehl 1961:14-16; Hussey 1970:27-31; Kazhdan \& Wharton Epstein 1985:11-13), tree op teen die keiserlike akademie en sy lede, en word deur latere skrywers, dalk ten onregte, daarvan beskuldig dat hy 33000 boeke vernietig het (Sandys 1921:395-396; Buckler 1961:216-217).

In die 9de eeu beleef die Bisantynse wêreld 'n ekonomiese en kulturele oplewing wat tot die begin van die 13de eeu sou voortduur (Kazhdan \& Wharton Epstein 1985:14-31). Dat die Assistent-keiser Bardas in 863 die universiteit in Konstantinopel herorganiseer het (Sandys 1921:395-396), word in onlangse studies bevraagteken (Kazhdan \& Wharton Epstein 1985:121-123). Tog ontwikkel skool- en universiteitsopvoeding aanhoudend, en vertoon die Griekse Ooste teen die 11de eeu 'n hoër vlak van geletterdheid as die Latynse Weste, en was Konstantinopel aan die einde van die 12de eeu 'n belangrike intellektuele sentrum (Kazhdan \& Wharton Epstein 1985:120-129). In die nuwe intellektuele klimaat het die Klassieke tekste hernude kritiese aandag en waardering geniet. Naas die opspoor, kopiëring en versameling van ou tekste, het twee nuwe ontwikkelinge die proses van kopiëring bevorder en so talle ou Griekse boeke gered: die gebruik van die kleiner, vlotter minuskelskrif in plaas van die unksiale skrif, en die gebruik van papier wat via die Arabiere van die Sjinese aangeleer is. Die bewaring van die meeste Griekse werke wat nog vandag bestaan, is na hierdie fase herleibaar (Reynolds-Wilson 1968:51-52).

Die werk van twee figure bevorder die lot van die Klassieke werke in die 9de en 10de eeu. Photios (c. 810-891) het voor sy twee termyne as Patriarg van Konstantinopel (858-867, 877886) sy beroemde Bibliotheca, 'n versameling besprekings van antieke werke wat uit sy literêre gespreksgroep voortgekom het, geskryf. Die versameling bevat opsommings van en kommentaar oor baie werke (meestal geskiedskrywing, maar geen poësie nie) wat intussen verlore gegaan het. Ook sy Lexikon, wat in 1959 in 'n klooster in Macedonië ontdek is, bevat sitate uit verlore werke, poësie dié keer ingesluit (Sandys 1921:397-400; Wilamowitz 1982:68; Reynolds-Wilson 1968:53-56). Die werke van Photios reflekteer die Griekse outeurs wat in sy tyd gelees en bestudeer is o.a.: Homeros, Hesiodos, Pindaros, Aischulos, Sophokles, Euripides, Aristophanes, Theokritos, Thukidides, Plato, Demosthenes, Aristoteles, Plutarchos en Loukianos (Sandys 1921:402-403).

Die ander figur is Arethas (c. 860-935), leerling van Photios en ook 'n kerkman (hy was aartsbiskop van Caesarea in c. 907). Hy het monnike betaal om vir hom kopieë van ou Griekse tekste te maak. Van sy biblioteek het enkele boeke oorleef (o.a. Plato, Eukleides, Aristoteles se Organon, Aristeides, Loukianos, Cassius Dio, Philostratos, Pollux, Pausanias, Clemens Alexandrinus, Eusebios) en was sy eksemplaar van die Meditasies van Marcus Aurelius waarskynlik verantwoordelik vir die oorlewing van hierdie werk (Sandys 1921:403-404; Wilamowitz 1982:6-7; Reynolds-Wilson 1968:56). Sy manuskrip van Plato is in 895 vir hom gekopieer en in 1801 tussen 'n hoop verwaarloosde boeke op die vloer van die kloosterbiblioteek op die eiland Patmos deur E.D. Clarke ontdek en na Engeland geneem, waar dit vandag in die Bodleian-biblioteek in Oxford staan (codex Bodleianus Clarkianus 39) (Sandys 1921:404; Harvey 1984:83).

Die 10de eeu is deur Lemerle as "ensiklopedies" getipeer (Kazhdan \& Wharton Epstein 1985:14 n. 16, 14-15, 133). 'n Paar belangrike kompilasiewerke ontstaan in hierdie tyd. Die 
ensikJopediese versamelings van Keiser Konstantyn VII Porphyrogenitos (913-959) het veral historiese bronne ingesluit, waarvan baie nie meer bestaan nie; en die Souda-leksikon, wat deur 'n groep samewerkers opgestel is, bevat ' $n$ wye verskeidenheid van informasie wat op verlore bronne gebaseer is (Reynolds-Wilson 1968:58). Belangrik vir die Griekse epigrammatiese poësie is die Griekse Antologie, wat in c. 900 deur Konstantinos Kephalas saamgestel is. Sy bloemlesing het vorige versamelings van Meleagros, Philippos, Agathias en andere geïnkurporeer. Al hierdie bloemlesings het verlore gegaan, maar 'n groot gedeelte is teruggevind met die ontdekking van die codex Palatinus deur die Franse geleerde Salmasius in die Palatynse biblioteek in Heidelberg in 1607. Dit bevat 3700 epigramme wat in 980 deur ' $n$ onbekende redakteur versamel en in 15 boeke min of meer volgens tema gerangskik is.

Die wispelturige lotgevalle van 'n antieke manuskrip word goed aan die hand van codex Palatinus Graecus 23 geillustreer (kyk Beckby 1965:90-98). Sy geskiedenis tot 1600 is onbekend, maar daar word gemeen dat Giovanni Aurispa in 1421 dit met ander manuskripte van Konstantinopel na Italië gebring het. Spore daarvan lei vanaf Venesië, Verona, Bologna, Florence na Ferrara. In 1602 is dit aangekoop vir die Hertog Palatinus se biblioteek in Heidelberg. Gedurende die Dertigjarige Oorlog is Heidelberg in 1623 deur Johann Tserklaes, Hertog van Tilly, ingeneem, en is hierdie manuskrip saam met 3500 ander as 'n geskenk aan Pous Gregorius XV gestuur. Na sy verowering van Italië in 1797 het Napoleon 37 Palatynse manuskripte, waaronder ook die antologie, van Rome na Parys geneem. In 1815 het Pous Pius VII die Vatikaanse manuskripte in Parys teruggeëis; Heidelberg eis hulle as regmatig syne. Na onderhandelings is een deel (boeke 1-12) aan Heidelberg terugbesorg, maar die ander dele as "verlore of gesteel" verklaar. In 1839 vind F. Dübner die tweede deel in die Biblioteque Nationale in Parys gedurende die voorbereiding van sy teksuitgawe. Diplomatieke onderhandelings word in 1873 hervat, maar misluk. 'n Fotografiese afdruk van deel twee is uiteindelik verskaf. 'n Poging van die Duitse besettingsmag in Parys gedurende die Tweede Wêreldoorlog om die Parysgedeelte na Duitsland terug te neem, misluk. Vandag is die tweede deel van die Griekse Antologie steeds in Parys (codex Parisinus Suppl. Graecus 384).

Belangrike Griekse manuskripte wat uit die $10 \mathrm{de}$ eeu dateer is o.a. die codex Marcianus Graecus 454 van die llias met sy waardevolle scholia; die codex Ravennensis Graecus 429 van Aristophanes, die vroegste manuskrip met al 11 komedies; die codex Laurentianus 32.9 van Aischulos, die vroegste met al sewe tragedies; die codex Vaticanus Graecus 124 van Polubios; die codex Parisinus Graecus 2935 en Laurentianus 59.9 van Demosthenes (Reynolds-Wilson 1968:58).

Die volgende twee eeue lewer ' $n$ hele reeks belangrike figure op, wat deur hulle belangstelling in die heidense en Christelike Griekse boek, asook deur hulle vertroudheid met verlore werke wat in hulle eie werk gereflekteer is, tot die oorlewingstryd van antieke werke bydra: Michael Psellos (1018-1078), wat as professor in filosofie in Konstantinopel belangstelling in die Griekse letterkunde aangewakker het; Eustathios (fl. c. 1160-1192), wie se voorwoord tot sy kommentaar op die poësie van Pindaros en sy kommentare op die Ilias en Odusseia met baie uittreksels uit vroeëre skrywers nog bestaan; en Johannes Tzetzes (c. 1110-1180), wat in 'n didaktiese epos van 12,674 reëls meer as 400 skrywers aanhaal, en in sy ander werke allerlei mitologiese, literêre en historiese stof (nie altyd betroubaar nie!) insluit (Sandys 1921:411-439; Reynolds-Wilson 1968:59-68; Kazhdan \& Wharton Epstein 1985:133-136). Hierdie geleerdes was blykbaar die laaste Bisantyne om meer Griekse poësie as ons tot hulle beskikking te hê (Reynolds-Wilson 1968:62).

Met die inname van Konstantinopel op 13 April 1204 deur die Frankiese Vierde Kruistog ly die Griekse boek sy grootste ramp. Drie groot brande voor en na die inval vernietig Konstantinopel en daarmee duisende kosbare manuskripte wat vanaf die 4 de eeu vir bykans 
nege eeue daar veilige vesting en akademiese aandag geniet het (Sandys 1921:426). Gelukkig is heelwat Griekse boeke voor hierdie katastrofe reeds na die Weste, en veral Italië gebring. 'n Mate van intellektuele kontinuïteit het onder die Griekse keisers in Nikaia en in die res van die Bisantynse wêreld, asook in die suide van Italië voortgeduur.

Ná die restourasie van die Griekse heersers in 1261, het die onderwys en akademie, en daarmee die aandag aan Griekse tekste, weer in Konstantinopel en Thessaloniki onder die Palaiologoi (1261-1453) gefloreer (Hall 1968:43-44). Die monnik Maximus Planudes (c. 12551305 ) het Latyn geleer en etlike werke in Grieks vertaal, 'n katalogus van Plutarchos se werke saamgestel, die Griekse Antologie hersien en uitgebrei, en manuskripte versamel (Sandys 1921:427-428; Reynolds-Wilson 1968:64-65). Sy eksemplaar van die Griekse Antologie, wat tot die ontdekking van die Palatynse Antologie in 1607 die enigste bron van die Griekse epigramme was, word vandag in die Biblioteca Marciana in Venesië bewaar (Sandys 1921:428).

Die onderwyser Demetrios Triklinios (vroeë 14de eeu) het self manuskripte versamel, gekopieer en geannoteer, op grond van metriese oorwegings gekorrigeer, en die scholia geredigeer. Die kopieë van sy eksemplaar van nege tragedies van Euripides is ons enigste bron vir die huidige teks van hierdie werke (Reynolds-Wilson 1968:65-67). Ongelukkig was Triklinios, net soos ander geleerdes van sy tyd, geneig om die ou Griekse tekste met minder respek te behandel. Skade is vir eeue daarna aangerig deur hulle onakkurate geleerdheid en lukrake gepeuter aan die teks. Tog was hulle die skakel met die ou wêreld en die naderende Renaissance. Sonder hulle sou die Renaissance in Italië onmoontlik of ten minste anders gewees het (Sandys 1921:427, 431, 434-436).

\section{BIBLIOGRAFIE}

Beckby, H. 1965. Anthologia Graeca, vol. 1. München: Heimeran. 2de verbeterde uitgawe.

Buckler, Georgina. 1961. "Byzantine education", in Baynes, N.H. \& Moss, H.St.L.B. '(reds.), Byzantium. An Introduction to East Roman Civilization, 200-220. Oxford: Clarendon Press.

Hall, F.W. 1968. A companion to classical texts. Hildesheim: Georg Olms [1931. Oxford: Clarendon Press].

Harvey, P. 1984. The Oxford companion to classical literature. Oxford: University Press [1937].

Kazhdan, A.P. \& Wharton Epstein, Ann. 1985. Change in Byzantine culture in the eleventh and twelfth centuries. Berkeley/Los Angeles/Londen: University of California Press.

Moss, H.St.L.B. \& Diehl, C. 1961. "The history of the Byzantine empire: an outline", in Baynes, N.H. \& Moss H.St.L.B. (reds.), Byzantium. An introduction to East Roman civilization, 1-50. Oxford: Clarendon Press [1948].

Reynolds, L.D. \& Wilson, N.G. 1968. Scribes and scholars. A guide to the transmission of Greek \& Latin literature. Oxford: University Press.

Sandys, J.E. 1921. A history of classical scholarship, vol. 1. 3de uitgawe. Cambridge: University Press. Herdruk 1967. New York/Londen: Hafner Publishing Company.

Wilamowitz-Moellendorff, U. von. 1982. History of classical scholarship. Eng. vertaling deur A. Harris, met Inleiding deur H. Lloyd-Jones. Londen: Duckworth [1921. Leipzig: Teubner]. 